\title{
Meteorological Drought Assessment in Sharjah, UAE Using Drought Indices
}

\author{
Mhamd S. Oyounalsoud, Arwa Najah, Abdullah G. Yilmaz, Mohamed Abdallah, and Mohsin Siddique
}

\begin{abstract}
Drought is a natural disaster that significantly affects environmental and socio-economic conditions. It occurs when there is a period of below average precipitation in a region, and it results in water supply shortages affecting various sectors and life adversely. Droughts impact the ecosystems, crop production, and erode livelihoods. Monitoring drought is essential especially in the United Arab Emirates (UAE) due to the scarcity of rainfall for an extended period of time. In this study, drought is assessed in Sharjah UAE using monthly precipitation and average temperature data recorded for 35 years (1981-2015) at the Sharjah International Airport. The standardized precipitation Index (SPI), and the Reconnaissance Drought Index (RDI) are selected to predict future droughts in the region. SPI and RDI are fitted to the statistical distribution functions (gamma and lognormal) in an annual time scale and then, a trend analysis of index values is carried out using Mann-Kendal test. The correlation between SPI and RDI indices was found to be high where both showed high drought frequencies and a tendency to get drier over time, thus indicating the need of appropriate drought management and monitoring.
\end{abstract}

Index Terms-Drought, climate change, precipitation, SPI, RDI.

\section{INTRODUCTION}

Drought is a complex natural phenomenon that results in serious economic, environmental, and social impacts. The effects of drought accumulate slowly, and its impacts spread over a larger geographical area than other natural hazards [1]. Droughts results in prolonged water supply shortages adversely impacting ecosystems, agriculture, and residents in a region. Annual global economic loss caused by drought is around 6-8 billion US dollars [2].

Droughts occur when there are prolonged periods of rainfall deficiency for a season or more causing decreases in stream flows and water levels in lakes and reservoirs. In addition to climatic factors, human activities such as deforestation, construction, and agriculture negatively impact the water cycle and cause droughts. Other causes such as soil moisture depletion and increases in surface temperatures are likely to result in more severe droughts [3]. Over the last century, global warming has emerged as another major driver

Manuscript received April 30, 2021; revised June 23, 2021. The authors would like to thank the Bureau of Metrology, the executive agency of the Australian Government for providing the rainfall and temperature data.

M. S. Oyounalsoud is with the University of Sharjah, Sharjah, UAE (e-mail: U18200511@sharjah.ac.ae).

A. Najah is with Khalifa University, AbuDhabi, UAE (e-mail: 100057968@ku.ac.ae).

A. G. Yilmaz is with the Engineering Department, La Trobe University, Melbourne, Australia (e-mail: G.Yilmaz@latrobe.edu.au).

M. Abdallah and M. Sidiqque are with the University of Sharjah, Sharjah, UAE (e-mail: mabdallah@sharjah.ac.ae,msiddique@sharjah.ac.ae). of severe droughts. Global warming causes change in several climate variables, namely precipitation, humidity, and wind speed, which lead to more frequent flood and drought events.

The Middle East and North Africa (MENA) region is one of the most climate change sensitive regions in the World. Barlow [4] reported significant temperature increase with a rise in the number of warm days and heat-wave events. Climate change has significant effects on water resources availability and management in MENA region. Even though climate change and drought studies are very important from many points of views, there are very limited studies for the same in the MENA region. Kelley [5] studied drought in Syria and reported that the drought conditions have been aggravated due to human-induced climate change. Hameed [6] investigated meteorological drought over Iraq during the period of 1948-2009 and showed that a drying trend over Iraq with severe to extreme drought conditions was governing the first decade of the $21^{\text {st }}$ century. Prudhomme [7] also reported an increase of drought days by more than $50 \%$ around the Mediterranean by the end of the $21^{\text {st }}$ century for representative concentration pathways (RCP)8.5. AlEbri [8] showed the effects of El Niño and La Niña on weather patterns and specifically on rainfall. They have discovered that the United Arab Emirates (UAE) continues to face challenges that are related to adaptation to weather and climate change, where they linked the fluctuations of weather in the UAE to El Niño and La Niña. Sherif [9] conducted an analysis of rainfall and drought in the UAE and found that the average drought duration is about 2.8 years in the UAE, which classifies the country as an arid region.

Evidently, limited studies considered climate change in drought analysis using future climate projections. Forecasting climate change is important, specifically drought, how it is changing over time, and impacts on sustainability and society functioning. In this study, climate change effects on droughts are investigated. The emirate of Sharjah located in the UAE is the selected study area due to availability of long-term relevant climate data and tremendous need of water to meet the growing demand over the past few decades. Climate change effects on droughts in Sharjah are investigated by calculating the Standardized Precipitation Index (SPI), Reconnaissance Drought Index (RDI), as well as trend analysis. The outcome of this study will make a significant contribution to climate change and drought studies. It will also aid in providing successful drought management in the study area.

\section{STUDY AREA AND DATA}

The Emirate of Sharjah is located in UAE covering an area of approximately $2,600 \mathrm{~km}^{2}$ with a total population of 1.4 
million. The Sharjah Emirate falls on coordinates of $25.3^{\circ} \mathrm{N}$ $55.5^{\circ} \mathrm{E}$ along the southern coast of the Arabian Gulf on the Arabian Peninsula as shown in Fig. 1. Sharjah is classified as a dessert with hot climate and characterized with its great arid land. Sharjah has mean annual temperature of $18-34^{\circ} \mathrm{C}$. Rain in Sharjah occurs lightly and infrequently with an average of $100 \mathrm{~mm} /$ year. The rainfall season occurs from November to March, and about two-thirds of the year's rainfalls concentrate between February and March.

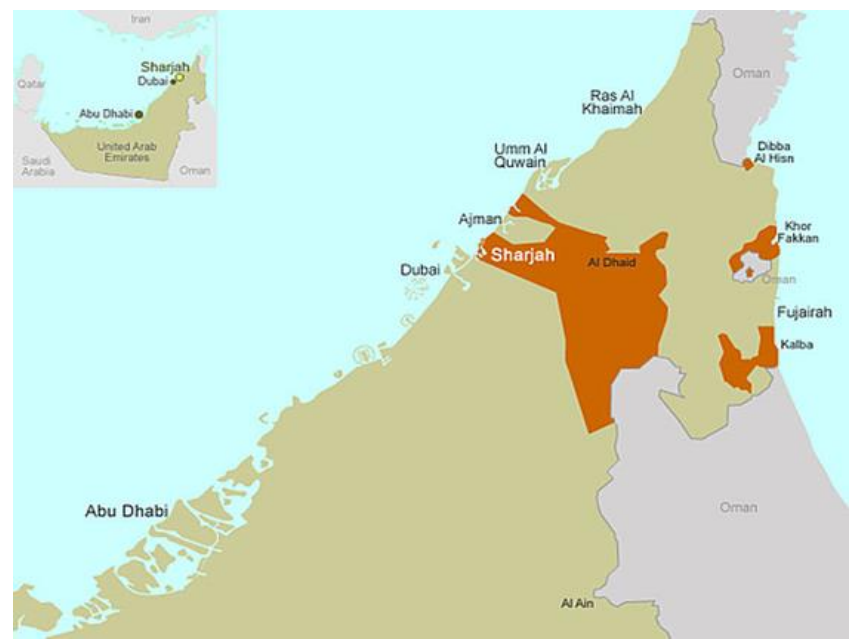

Fig. 1. Location of Sharjah, UAE (Source: Universes in Universe, 1997).

Two types of monthly precipitation data sets were used in this study: (1) Observed monthly rainfall data over the period of 1981 to 2015, (2) Future (projected) data from Global Climate Models (GCMs) for two different periods: near future for the period of 2030 to 2064, and far future for the period of 2065 to 2099. Observed data were received from weather observation station at the Sharjah International Airport. Future data projections were obtained from four GCMs NASA Goddard Institute for Space Sciences E2 meteorological Research Institute model (MRI_CGCM3) as recommended by Yilmaz [10].

\section{Methodology}

This study consists of five main steps including (1) Calculation of SPI, Aridity Index (AI), and RDI. (2) Drought occurrence evaluation. (3) Trend analysis of drought indices (5) Goodness of fit analysis.

\section{A. Calculation of Drought Indices}

Drought indices are essential elements for an efficient drought monitoring system. SPI, AI, and RDI are the commonly adopted indices in the literature [11], [12] due to the advantages offered by those indices for analyzing drought.

\section{1) Standardize precipitation index (SPI)}

SPI is a widely adopted index in various drought-related applications worldwide because of its flexibility and the dependency on only precipitation [13], [14]. SPI's main strength is that it can be computed for different timescales (e.g., 1, 3, 6, 12, 24 months). The impact of drought on the availability of the water resources is casted in those timescales. Relatively short scale can monitor soil moisture conditions, where the longer-term precipitation anomalies are reflected by groundwater, streamflow, and reservoir storage. Long-term (30 year or more monthly data) precipitation record is required to calculate SPI for any location. The precipitation time series is then fit to a probability distribution, which is transformed into normal distribution with an average SPI value equal to zero. This makes positive values wet and negative values dry [15]. The classification scale used to define drought events resulting from the SPI is shown in Table I.

\begin{tabular}{cc}
\multicolumn{2}{c}{ TABLE I: SPI CLASSIFICATION } \\
\hline \hline SPI Values & Class \\
\hline+2.0 and more & Extremely wet \\
1.5 to 1.99 & Very wet \\
1.0 to 1.49 & Moderately wet \\
-0.99 to 0.99 & Near normal \\
-1.0 to -1.49 & Moderately dry \\
-1.5 to -1.99 & Severely dry \\
-2.0 and less & Extremely dry \\
\hline \hline
\end{tabular}

For precipitation time series, gamma distribution is originally used for SPI calculation [16]. In addition to gamma distribution, many researchers have used the log-normal distribution, which also provided reliable results. The term "magnitude" refers to the positive sum of the SPI for all the months within a drought event. Table II presents the classification of drought magnitude depending on the probability of occurrence of drought events [17], as well as the probability of the precipitation necessary to end it [13].

TABLE II: ThE ClASSIFICATION OF DROUGHT MAGNITUdE DEPENDING ON THE PROBABILITY OF OCCURRENCE OF DROUGHT EVENTS

\begin{tabular}{cccc}
\hline \hline SPI & Category & $\begin{array}{c}\text { Number of } \\
\text { times in } \\
100 \text { years }\end{array}$ & Severity of event \\
\hline \hline 0 to -0.99 & Mild dryness & 33 & 1 in 3 yrs. \\
-1.00 to -1.49 & Moderate dryness & 10 & 1 in 10 yrs. \\
-1.5 to -1.99 & Severe dryness & 5 & 1 in 20 yrs. \\
$<-2.0$ & Extreme dryness & 2.5 & 1 in 50 yrs. \\
\hline \hline
\end{tabular}

The probability density function of the gamma distribution is defined as:

$$
g(x)=\frac{1}{\beta^{\alpha} \Gamma(\alpha)} x^{\alpha-1} e^{-x / \beta} \text { for } x>0
$$

where $\alpha$ is a shape parameter $(\alpha>0), \beta$ is a scale parameter $(\beta>$ $0),(x>0)$ is the amount of effective precipitation, and $\Gamma(\alpha)$ is the gamma function, expressed as $\int_{0}^{\infty} y^{\alpha-1} e^{-y} \mathrm{dy}$.

The parameters $\alpha$ and $\beta$ are estimated through the following formulation:

$$
\hat{\alpha}=\frac{1}{4 \mathrm{~A}}\left(1+\sqrt{1+\frac{4 \mathrm{~A}}{3}}\right), \quad \hat{\beta}=\bar{x} / \hat{\alpha}
$$

where $\mathrm{x}^{-}$is mean precipitation and $\mathrm{A}$ is given by $\mathrm{A}=$ $\ln (\bar{x})-n^{-1} \sum \ln (x)$ and $\mathrm{n}$ is the number of observations.

The cumulative probability, $\mathrm{G}(\mathrm{x})$, of a precipitation event is

$$
G(x)=\frac{1}{\widehat{\beta}^{\widehat{\alpha}} \Gamma(\widehat{\alpha})} \int_{0}^{\chi} x^{\widehat{\alpha}} e^{-x / \widehat{\beta}} d x
$$

Letting $=x / \hat{\beta}$, the expression is reduced to incomplete gamma function: 


$$
G(x)=\frac{1}{\Gamma(\widehat{\alpha})} \int_{0}^{\chi} t^{\widehat{\alpha}-1} e d t
$$

Given that gamma distribution is not defined for $\mathrm{x}=0$, and the probability of zero precipitation $(q)$, the cumulative probability becomes

$$
H(x)=q+(1-q) \mathrm{G}(x)
$$

For SPI calculation, the cumulative probability distribution is transformed into normal distribution using the following approximation [18]:

$$
\alpha \mathrm{SPI}=-\left(t-\frac{c_{0}+c_{1} t+c_{2} t^{2}}{1+d_{1} t+d_{2} t^{2}+d_{3} t^{3}}\right), 0<H(x) \leq 0.5
$$

in which $t=\sqrt{\ln \left(1 / H(x)^{2}\right.}$

$$
\alpha \mathrm{SPI}=t-\frac{c_{0}+c_{1} t+c_{2} t^{2}}{1+d_{1} t+d_{2} t^{2}+d_{3} t^{3}}, 0.5<H(x) \leq 1.0
$$

in which $t=\sqrt{\ln \left(1 /\left(1-H(x)^{2}\right)\right.}$

In approximation, following constants are used: $\mathrm{c}_{0}=$ $2.515517, \mathrm{c}_{1}=0.802853, \mathrm{c}_{2}=0.010328, \mathrm{~d}_{1}=1.43278, \mathrm{~d}_{2}=$ $0.189269, \mathrm{~d}_{3}=0.001308$. The probability density function of a lognormal distribution is defined as [19], [20]:

$$
f(x ; \mu, \sigma)=\frac{1}{x \sigma \sqrt{2 \pi}} \exp \left(-\frac{(\ln x-\mu)^{2}}{2 \sigma^{2}}\right), x>0
$$

where $\mu$ is the scale parameter and $\sigma$ is the shape parameter calculated as:

$$
\begin{gathered}
\hat{\mu}=n^{-1} \sum_{k} \ln x_{k} \\
\hat{\sigma}^{2}=n^{-1} \sum_{k}\left(\ln x_{k}-\hat{\mu}\right)^{2}
\end{gathered}
$$

\section{2) Reconnaissance drought index (RDI)}

RDI is characterized as a general meteorological index for the drought assessment of severity and duration, and to approach the water deficit in a more accurate way, as a sort of balance between input and output in a water system [21], [22] The RDI is based both on precipitation $(\mathrm{P})$ and potential evapotranspiration (PET). The $\alpha_{k}$ is usually calculated for the $\mathrm{i}^{\text {th }}$ year and a time basis $\mathrm{k}$ (months) using the following equation:

$$
\alpha_{k}^{(i)}=\frac{\sum_{j=1}^{k} P_{i j}}{\sum_{j=1}^{k} P E T_{i j}}
$$

where $P_{i j}$ and $P E T_{i j}$ are the precipitation and potential evapotranspiration of month $j$ of hydrological year $i$. In this study, Thornthwaite method was used to calculate the PET as similar to [23]-[25].

\section{B. Trend Analysis}

After calculation of indices, Mann-Kendal (MK) was applied to detect trends. MK is a rank based nonparametric test that was developed by Mann and Kendall for detecting linear or non-linear trends [26] and it is commonly used in hydro-meteorological trend analysis [27], [28].

\section{RESUlTS AND DISCUSSION}

\section{A. Drought Evaluation}

The calculated RDI and SPI values did not show a consistent pattern over the observed data period, 1981 and 2015 as shown in Figure II. The wetter years with highest positive index value (very to extremely wet years) were 1982, 1995 and 1997. On the other hand, the lowest index value representing the drier years were 1985 and 2001. In near future period (2030 to 2064), the highest index value was observed in year 2046 (RDI is 2.18, whereas SPI is 2.11), and the lowest index value was detected in 2034 (RDI is -1.59 and SPI is -1.74). Similarly, the drought values of the future years from 2065 to 2099 raised significantly in some years such as 2079 and 2081 with drought values of 1.83 and 1.94 based on SPI, respectively. Further, a steep drop was observed in RDI in 2069 (-1.66) and 2085 (-1.65). This drop caused a severely dry period in these two years. The decreasing trend line shown in Figure II demonstrates a drier future. Based on comparison between the two indices, RDI values had stronger decreasing trends relative to the SPI values.

Table III gives occurrence of drought events by percentage, and it can be observed that more than $60 \%$ of the years were classified as near normal condition in observed, near future, and far future periods. While the percentages ranged from 5.7 to $\mathbf{1 4 . 3}$ for moderately and severely drought conditions respectively, it is important to note that extremely dry conditions were detected in lognormal distribution-based SPI (ranging from 2.9 to $5.7 \%$ ).

When looking into the two indices, SPI (gamma) had relatively lower drought occurrences in comparison to the other index and distribution. But overall, the two indices and distributions had similar behavior in classifying the drought events in the different years.

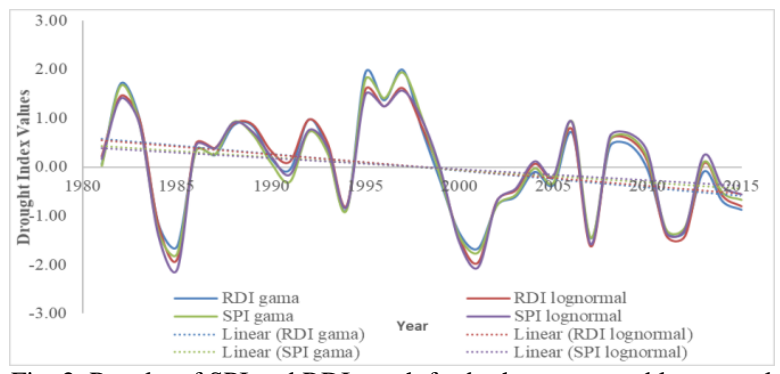

Fig. 2. Results of SPI and RDI graph for both gamma and lognormal observations.

As discussed above, the gamma and lognormal distributions were used in calculation of SPI and RDI values. The performance of these two distributions based on goodness of fit analysis is checked using Anderson-Darling, Kolmogorov-Smirnov, and Chi-squared tests. Based on analysis given in Table IV, these three tests agreed that both distributions fitted the data well in both indices.

According to the Chi-squared test, the Gamma function showed better results in comparison of the lognormal distribution with few exceptions including observed and far future for RCP6 and RCP8.5. 
TABLE III: OCCURRENCE OF DROUGHT EVENTS PERCENTAGES Occurrence of drought events (\%)

\begin{tabular}{|c|c|c|c|c|c|c|c|c|c|c|c|c|}
\hline \multirow{3}{*}{$\begin{array}{c}\text { Drought } \\
\text { classification }\end{array}$} & \multicolumn{4}{|c|}{ Observed } & \multicolumn{4}{|c|}{ Near Future } & \multicolumn{4}{|c|}{ Far Future } \\
\hline & \multicolumn{2}{|c|}{ SPI } & \multicolumn{2}{|c|}{ RDI } & \multicolumn{2}{|c|}{ SPI } & \multicolumn{2}{|c|}{ RDI } & \multicolumn{2}{|c|}{ SPI } & \multicolumn{2}{|c|}{ RDI } \\
\hline & Gamma & $\log$ & Gamma & $\log$ & Gamma & $\log$ & Gamma & $\log$ & Gamma & $\log$ & Gamma & $\log$ \\
\hline Near normal & 65.7 & 68.6 & 68.6 & 68.6 & 65.7 & 65.7 & 68.6 & 68.6 & 68.6 & 68.6 & 65.7 & 65.7 \\
\hline Moderately dry & 14.3 & 8.6 & 14.3 & 11.4 & 8.6 & 5.7 & 11.4 & 8.6 & 8.6 & 5.7 & 11.4 & 8.6 \\
\hline Severely dry & 5.7 & 5.7 & 5.7 & 8.6 & 8.6 & 8.6 & 8.6 & 11.4 & 8.6 & 5.7 & 8.6 & 11.4 \\
\hline Extremely dry & 0.0 & 5.7 & 0.0 & 0.0 & 0.0 & 2.9 & 0.0 & 0.0 & 0.0 & 5.7 & 0.0 & 0.0 \\
\hline
\end{tabular}

TABLE IV: GOODNESS OF FIT RESULTS

\begin{tabular}{|c|c|c|c|c|c|c|c|c|c|c|c|c|c|}
\hline & & \multicolumn{4}{|c|}{ Anderson-Darling } & \multicolumn{4}{|c|}{ Kolmogorov-Smirnov } & \multicolumn{4}{|c|}{ Chi-squared } \\
\hline & & \multicolumn{2}{|c|}{ SPI } & \multicolumn{2}{|c|}{ RDI } & \multicolumn{2}{|c|}{ SPI } & \multicolumn{2}{|c|}{ RDI } & \multicolumn{2}{|c|}{ SPI } & \multicolumn{2}{|c|}{ RDI } \\
\hline \multicolumn{2}{|c|}{ Time period } & Gamma & $\log$ & Gamma & $\log$ & Gamma & $\log$ & Gamma & $\log$ & Gamma & $\log$ & Gamma & $\log$ \\
\hline \multicolumn{2}{|c|}{ Observed } & 0.30 & 0.57 & 0.27 & 0.52 & 0.10 & 0.12 & 0.07 & 0.13 & 1.62 & 2.08 & 0.89 & 1.33 \\
\hline \multirow{4}{*}{$\begin{array}{c}\text { Near } \\
\text { Future }\end{array}$} & RCP2.6 & 0.27 & 0.47 & 0.27 & 0.52 & 0.08 & 0.10 & 0.08 & 0.10 & 0.40 & 2.04 & 0.36 & 2.11 \\
\hline & RCP4.5 & 0.27 & 0.52 & 0.31 & 0.55 & 0.08 & 0.10 & 0.11 & 0.10 & 0.36 & 2.11 & 0.19 & 1.99 \\
\hline & RCP6 & 0.27 & 0.54 & 0.34 & 0.64 & 0.08 & 0.11 & 0.11 & 0.12 & 0.88 & 1.51 & 1.29 & 3.30 \\
\hline & RCP8.5 & 0.30 & 0.55 & 0.33 & 0.57 & 0.08 & 0.11 & 0.12 & 0.11 & 1.09 & 2.09 & 0.80 & 0.93 \\
\hline \multirow{4}{*}{$\begin{array}{c}\text { Far } \\
\text { Future }\end{array}$} & RCP2.6 & 0.30 & 0.52 & 0.29 & 0.52 & 0.09 & 0.13 & 0.11 & 0.13 & 4.92 & 2.21 & 2.60 & 0.88 \\
\hline & RCP4.5 & 0.24 & 0.42 & 0.25 & 0.49 & 0.09 & 0.09 & 0.11 & 0.11 & 1.08 & 1.56 & 0.11 & 2.08 \\
\hline & RCP6 & 0.30 & 0.50 & 0.32 & 0.55 & 0.10 & 0.13 & 0.12 & 0.12 & 2.26 & 2.04 & 5.12 & 2.81 \\
\hline & RCP8.5 & 0.33 & 0.55 & 0.38 & 0.62 & 0.09 & 0.12 & 0.13 & 0.12 & 2.29 & 2.28 & 5.85 & 1.40 \\
\hline
\end{tabular}

\section{B. Trend Analysis}

As mentioned earlier, MK test was used to examine the trends in drought indices. Table $\mathrm{V}$ shows the $\mathrm{z}$ statistics values of each index for three periods (observed, near and far future) and four RCPs. It should be noted that the bold numbers in Table $\mathrm{V}$ represent the statistically significant trends with $90 \%$ significance level. Further, as can be seen in Table V, all z-statistics were negative indicating a decreasing trend (drier trend). Although decreasing trends were calculated for SPI values, none of those values are statistically significant. On the other hand, majority of (decreasing) trends in RDI are statistically significant.

TABLE V: TREND ANALYSIS RESULTS

\begin{tabular}{clcccc}
\hline \hline & & \multicolumn{2}{c}{ SPI } & \multicolumn{2}{c}{ RDI } \\
\multicolumn{2}{c}{ Time period } & Gamma & Lognormal & Gamma & Lognormal \\
\hline \hline \multicolumn{2}{c}{ Observed } & -1.449 & -1.449 & $\mathbf{- 2 . 0 4 5}$ & $\mathbf{- 2 . 0 3 1}$ \\
\hline \hline \multirow{2}{*}{ Near } & RCP2.6 & -1.051 & -1.037 & -1.619 & -1.576 \\
Future & RCP4.5 & -1.079 & -1.079 & -1.576 & -1.591 \\
& RCP6.0 & -1.122 & -1.108 & $\mathbf{- 1 . 7 3 3}$ & $\mathbf{- 1 . 7 0 4}$ \\
& RCP8.5 & -1.108 & -1.108 & $\mathbf{- 1 . 6 7 6}$ & $\mathbf{- 1 . 6 7 6}$ \\
\hline \hline \multirow{2}{*}{ Far } & RCP2.6 & -1.207 & -1.207 & $\mathbf{- 1 . 6 9}$ & $\mathbf{- 1 . 7 0 4}$ \\
Future & RCP4.5 & -1.051 & -1.065 & $\mathbf{- 1 . 7 4 7}$ & $\mathbf{- 1 . 7 7 5}$ \\
& RCP6 & -1.065 & -1.065 & $\mathbf{- 1 . 6 4 7}$ & -1.633 \\
& RCP8.5 & -1.094 & -1.079 & $\mathbf{- 1 . 7 7 5}$ & $\mathbf{- 1 . 7 7 5}$ \\
\hline \hline
\end{tabular}

\section{CONCLUSION}

In this study, droughts in Emirates of Sharjah, UAE was assessed by quantifying droughts using RDI and SPI indices. For analysis, observed monthly rainfall data of the period of 1981-2015 and future (projected) data including near future for the period of 2030-2064 and far future for the period of 2065-2099 under four different RCPs are used. The SPI and RDI indices were generated through fit of the data to gamma and lognormal distributions, and the goodness of fits were evaluated using Anderson-Darling, Kolmogorov-Smirnov, and Chi-squared tests. Temporal trends in index values were also investigated using MK test to identify changes in index values (level of drought) over years. To sum up the major points of this study, it significant to mention the trend and correlation status. The decreasing trends in index values were detected indicating a drier future, RDI gave stronger decreasing trends in comparison to SPI, the correlation between the SPI and RDI was very high for all data periods (observed, near and far future) and all RCPs. More than $60 \%$ of the years were classified as near normal drought condition, while the 5.7 to $14.3 \%$ of years showed of moderately and severely drought status. The Gamma distribution function outperformed lognormal distribution in goodness of fit. Finally, to comprehensively investigate drought levels and trends over the entire UAE, based on the present study, it is recommended to extend the methodology presented herein to include observed data from several stations and the future projection of global climate models suitable for study area.

\section{CONFLICT OF INTEREST}

The authors declare no conflict of interest.

\section{AUTHOR CONTRIBUTIONS}

Abdullah Yilmaz conducted the research; Mhamd Oyounalsoud \& Arwa Najah analyzed the data and wrote the paper; Abdullah Yilmaz, Mohamad Abdallah \& Mohsin Siddique reviewed and edited the paper.

\section{ACKNOWLEDGMENT}

The authors would like to thank the Bureau of Metrology, the executive agency of the Australian Government for providing the rainfall and temperature data.

\section{REFERENCES}

[1] M. Azarakhshi, M. Mahdavi, H. Arzani, and H. Ahmadi, “Assessment of the Palmer drought severity index in arid and semi-arid rangeland: (Case study: Qom province, Iran)," Desert, vol. 16, no. 2, pp. 77-86, 2011.

[2] D. A. Wilhite, Drought As a Natural Hazard: Concepts and Definitions, 2000 .

[3] N. Jovanovic, C. Petersen, and H. Masinge, A Critical Review of Drought Research: Physical Characteristics, Perceptions, Adaptation Strategies and Practices, 2020. 
[4] M. Barlow, B. Zaitchik, S. Paz, E. Black, J. Evans, and A. Hoell, "A review of drought in the Middle East and southwest Asia," Journal of Climate, vol. 29, no. 23, pp. 8547-8574, 2016

[5] C. P. Kelley, S. Mohtadi, M. A. Cane, R. Seager, and Y. Kushnir, "Climate change in the fertile crescent and implications of the recent Syrian drought," in Proc. the national Academy of Sciences, vol. 112 no. 11, pp. 3241-3246, 2015

[6] M. Hameed, A. Ahmadalipour, and H. Moradkhani, "Apprehensive drought characteristics over Iraq: results of a multidecadal spatiotemporal assessment," Geosciences, vol. 8, no. 2, p. 58, 2018.

17] C. Prudhomme et al., "Hydrological droughts in the 21 st century, hotspots and uncertainties from a global multimodel ensemble experiment," in Proc. the National Academy of Sciences, vol. 111, no. 9, pp. 3262-3267, 2014.

[8] M. AlEbri, H. Arman, and A. Shalaby, "The impact of El Niño and La Niña on the United Arab Emirates (UAE) rainfall," General Scientific Research, vol. 4, pp. 5-10, 2016.

[9] M. Sherif, M. Almulla, A. Shetty, and R. K. Chowdhury, "Analysis of rainfall, PMP and drought in the United Arab Emirates," International Journal of Climatology, vol. 34, no. 4, pp. 1318-1328, 2014.

[10] A. G. Yilmaz and A. G. Shabib, "Rainfall and air temperature projections for Sharjah City, United Arab Emirates," International Journal of Water, vol. 13, no. 1, pp. 60-79, 2019.

[11] S. M. Vicente-Serrano et al., "Performance of drought indices for ecological, agricultural, and hydrological applications," Earth Interactions, vol. 16, no. 10, pp. 1-27, 2012.

[12] A. Moghbeli, M. Delbari, and M. Amiri, "Application of a standardized precipitation index for mapping drought severity in an arid climate region, southeastern Iran," Arabian Journal of Geosciences, vol. 13, no. 5, pp. 1-16, 2020.

[13] T. B. McKee, N. J. Doesken, and J. Kleist, "The relationship of drought frequency and duration to time scales," in Proc. the 8th Conference on Applied Climatology, vol. 17, no. 22, pp. 179-183, 1993.

[14] D. Tigkas, "Drought characterisation and monitoring in regions of Greece," European Water, vol. 23, no. 24, pp. 29-39, 2008.

[15] C. D. C. Edwards, T. B. McKee, N. J. Doesken, and J. Kleist, "Historical analysis of drought in the United States," in 77th Conference on Climate Variations, 77th AMS Annual Meeting, pp. 2-7, 1997.

[16] H. C. Thom, "A note on the gamma distribution," Monthly Weather Review, vol. 86, no. 4, pp. 117-122, 1958.

[17] G. Tsakiris, D. Pangalou, and H. Vangelis, "Regional drought assessment based on the reconnaissance drought index (RDI)," Water Resources Management, vol. 21, no. 5, pp. 821-833, 2007.

[18] M. Abramovitz and I. A. Stegun, Handbook of Mathematical Functions, chapter 16, 1965.

[19] J. Bartosova, "Logarithmic-normal model of income distribution in the Czech Republic,” Austrian J. Stat., vol. 35, pp. 215-222, 2006.

[20] D. Bilkova, "Lognormal distribution and using L-moment method for estimating its parameters," Int. J. Math. Models Methods Appl. Sci., vol. 6 , pp. 30-44, 2012.

[21] G. Tsakiris and H. J. E. W. Vangelis, "Establishing a drought index incorporating evapotranspiration," European Water, vol. 9, no. 10, pp. 3-11, 2005 .

[22] G. Tsakiris, I. Nalbantis, D. Pangalou, D. Tigkas, and H. Vangelis, "Drought meteorological monitoring network design for the reconnaissance drought index (RDI)," in Proc. the 1st International Conference "Drought Management: Scientific and Technological Innovations," Zaragoza, Spain: option Méditerranéennes, Series A (No. 80, p. 2008), 2008.

[23] S. Gond and N. Gupta, Evaluation of Drought Severity Indices and their Trend for Mirzapur (Uttar Pradesh) Evaluation of Drought Severity Indices and their Trend for Mirzapur (Uttar Pradesh), 2020.

24] H. I. Z. Al-Sudani, "Derivation mathematical equations to estimate water surplus and groundwater recharge in Iraq," Applied Water Science, vol. 10, no. 4, pp. 1-11, 2020.

[25] J. F. R. Vera, Y. E. Z. Mera, and M. Á. Pérez-Martín, “Adapting water resources systems to climate change in tropical areas: Ecuadorian coast," Science of the Total Environment, vol. 703, p. 135554, 2020.

[26] M. Shadmani, S. Marofi, and M. Roknian, "Trend analysis in reference evapotranspiration using Mann-Kendall and Spearman's Rho tests in arid regions of Iran," Water Resources Management, vol. 26, no. 1, pp. 211-224, 2012

[27] C. Ndzabandzaba, "Change, variability and trend analysis of hydro-climatic time series," Climate Variability and Change in Africa, Springer, Cham., pp. 9-18, 2020.

[28] K. Sreelash et al., "Changes in the hydrological characteristics of Cauvery River draining the eastern side of southern Western Ghats, India," International Journal of River Basin Management, vol. 18, no. 2, pp. 153-166, 2020
Copyright (C) 2022 by the authors. This is an open access article distributed under the Creative Commons Attribution License which permits unrestricted use, distribution, and reproduction in any medium, provided the original work is properly cited (CC BY 4.0)

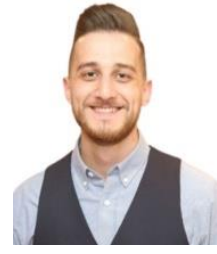

Mhamd Saifaldeen Oyounalsoud received his bachelor's degree in civil and Environmental Engineering from the University of Sharjah, UAE in 2019. He is conducting his master's degree at the University of Sharjah. His research interest area is climate change, drought assessment, and water resources.

He has been a teaching assistant at the Department of Civil \& Environmental Engineering (University of Sharjah) since 2019. He is currently working on developing a machine learning-based drought index for arid and semi-arid regions.

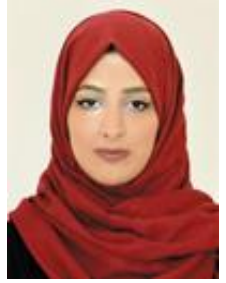

Arwa Najah is a master student in Water and Environmental Engineering Department at Khalifa University. She graduated from University of Sharjah as a civil and environmental engineer. Her research interests are climate change hydrology, drought assessment, and remote sensing applications in water resources. She is currently working on modeling the water quality of the Arabian gulf waters using remote sensing and space technology.

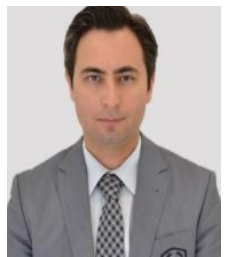

Abdullah Gokhan Yilmaz is currently working at La Trobe University, Melbourne in the Department of Engineering. His research interests are climate change hydrology, rainfall-runoff modelling, GIS and remote sensing applications in water resources management and extreme rainfall, flood, and drought analysis.

He has delivered variety of subjects at undergraduate and graduate levels including water resources engineering, fluid mechanics, thermo fluids, hydraulic engineering and design, engineering economics, irrigation water management and GIS in water resources engineering.

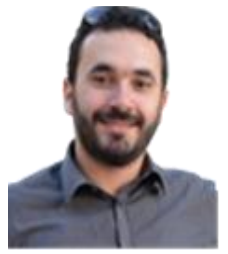

Mohamed Abdallah received his $\mathrm{PhD}$ in Environmental Engineering from the University of Ottawa, Canada in 2011. His area of specialization is environmental engineering, particularly integrated waste management, climate change mitigation, smart cities, sustainability, and life cycle assessment.

He has been an assistant professor at the Departmen of Civil \& Environmental Engineering since 2016 and is currently the coordinator of the MSc program in environmental science and engineering (University of Sharjah). He worked as a postdoctoral fellow in the Ottawa-Carleton Institute for Environmental Engineering. He is also a licensed Professional Engineer in Canada with 10 years of experience in leading private developers and international development agencies in North/South America, Asia, and Africa.

Dr. Abdallah has published his research work in many international refereed journals and conference proceedings. In his current position at the University of Sharjah, he was awarded internal and external research grants at around $\$ 300$ thousand and has published over twenty research papers mostly in high-ranked Q1 journals.

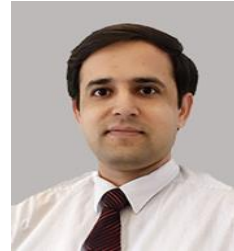

Mohsin Siddique is born in Pakistan in 1982. He received his $\mathrm{BSc}$ in civil engineering degree with honor in 2004 from University of Engineering and Technology Lahore, Pakistan, and MSc in civil engineering degree in 2007 and $\mathrm{PhD}$ in civil engineering degree in 2011 from the University of Tokyo, Japan

$\mathrm{He}$ started his teaching career at University of Engineering and Technology Lahore Pakistan in 2004 and currently he is working as Assistant Professor in the Department of Civil and Environmental Engineering at the University of Sharjah. His research interests include hydrologic and hydraulic processes, hydrodynamic modeling, wave transformations in surf zone and experimental investigations using high speed video image analysis.

Dr. Mohsin has served as reviewer for many journals and international conferences. Currently he is serving as member of SCIS research group and the leader of water resources management circle at University of Sharjah. 